\title{
Trendiness in human ARTs as technology transits from the macro to nano
}

\author{
David F. Albertini ${ }^{1}$
}

Published online: 19 April 2017

(C) Springer Science+Business Media New York 2017

There was a time when the status of research in any given field was within striking distance for trainees at the onset of an investigative career - not so today. The sheer quantity of data-laden papers on any given topic has increased exponentially over time. And upon the introduction of a new technology or experimental paradigm, newcomers and oldcomers alike must brace themselves for yet another onslaught of information and attendant protocols to keep apace. One recent example would be the subject of gene editing.

From a casual survey of PubMed, the rapidity and magnitude of "progress" in a breakthrough technology like gene editing is immediately evident. Consider that in 2006, a single paper appeared in the literature-yes, $n=1$. And for the year 2016, a total of 1050 publications on gene editing appeared, amounting to three orders of magnitude growth over a single decade. Given that the current preoccupation with CRISPR/ Cas9 genome tinkering is unlikely to subside anytime soon, this paradigm breaker of extreme proportions is here to stay and will undoubtedly change the face of genetic engineering in all kinds of organisms for better or worse.

Technology-based advances permeate all branches of medicine as the migration from perceptions at macroscales continues along a course of reductionism to the present day nano(molecular) scales with which we are becoming increasingly conversant. That we continue to adopt and explore applications in molecular genetics in the present day practice of human ARTs to potential benefits for patients is an admirable result of efforts in the field of reproductive medicine. That innovations like PGS are greeted as "trend-setting" is

David F. Albertini

dalbertini@thechr.com

1 The Center for Human Reproduction, New York, NY, USA unavoidable, as have many of the other adjuncts to traditional IVF (as we knew it) that have penetrated the infertility marketplace worldwide.

It is in this global context that, in spite of our reductionist appetite for paradigm breaking technologies, taking a retrospective look at ARTs over the same past decade alluded to above, sets trending and trendiness in ARTs back to a baseline that can be revealing to say the least. Such is the case in the recent article by Kushnir and colleagues who establish a number of interesting trends in the practice of human ARTs covering a time period from 2004 to 2013 [1]. Amongst their many findings, the link between changing technologies and outcomes is apparent in distinct ways amongst the various parts of the world where reliable data sets were available for analysis.

Compounding the matter of validating the worthiness for introducing new technologies in human ARTs is the most fundamental question of has it made a difference? To answer this question, Harper and colleagues have taken to task an analysis of the various adjuncts to human ARTs that have entered the domain of laboratory and diagnostic practices currently being enacted - albeit to varying degrees - in many countries around the world [2]. Their story is well worth the attention of our readership as well and and raises immediate concerns against the backdrop of commercial interests already embedded within reproductive medicine.

What comes from analyses of these kinds are questions prompting a closer look at the basic biology of human reproduction, in hopes of finding answers to the various inconsistencies or controversies of the day. And one example of this is illustrated this month by the paper from the group of Modi (see cover) [3]. Sagare-Patil and colleagues explore the mechanism by which progesterone alters sperm motility and the acrosome reaction, identifying HSP90 as a key mediator of these processes. What comes as no surprise is the finding of 
heterogeneity of HSP90 expression both between sperm in a single ejaculate and amongst sperm from men with varying levels of subfertility. In an age when paradigm breakers like gene editing are accompanied by the introduction of single cell "-omics," studies of this nature remind us of the drawbacks inherent to our current "averaging" methods that preclude what may, in the end, be a flawed strategy to select the best gametes and embryos for embryo transfer.

There is little question that single cell measurements are improving in sensitivity and accuracy with RNA seq, proteomic, and metabolomic platforms, that could and should enhance our ability to assess gamete [4] and embryo quality [5] for the betterment of ART practices. Keeping the trendiness in perspective will be a welcomed attitude as technologies pertinent to human ARTs continue to make their way into everyday laboratory and clinical endeavors.

\section{References}

1. Kushnir VA, Barad DH, Albertini DF, Darmon SK, Gleicher N. Systematic review of worldwide trends in assisted reproductive technology 2004-2013. Reprod Biol Endocrinol. 2017;15(1):6.

2. Harper J, Jackson E, Sermon K, Aitken RJ, Harbottle S, Mocanu E, et al. Adjuncts in the IVF laboratory: where is the evidence for 'addon' interventions? Hum Reprod. 2017:1-7.

3. Sagare-Patil V, Bhilawadikar R, Galvankar M, Zaveri K, Hinduja I, Modi D. Progesterone requires heat shock protein 90 (HSP90) in human sperm to regulate motility and acrosome reaction. J Assist Reprod Genet. 2017.

4. Ziegenhain C, Vieth B, Parekh S, Reinius B, Guillaumet-Adkins A, Smets M, et al. Comparative analysis of single-cell RNA sequencing methods. Mol Cell. 2017;65(4):631-43. e4

5. Wen J, Zeng Y, Fang Z, Gu J, Ge L, Tang F, et al. Single-cell analysis reveals lineage segregation in early post-implantation mouse embryos. J Biol Chem. 2017. 